\title{
The key determinant factors of clinical information systems user satisfaction: Lessons learnt from an Australian case study
}

\author{
Peter Haddad \\ Epworth HealthCare and Deakin University \\ peter.e.haddad@gmail.com
}

\author{
Nilmini Wickramasinghe \\ Epworth HealthCare and Deakin University \\ nilmini.work@gmail.com
}

\begin{abstract}
Driven by the escalating pressures to enhance its outcomes within its limited resources, the healthcare industry is increasingly investing in various clinical information systems. Although user satisfaction is key to realizing the benefits of these large invests, the determinant factors for user satisfaction with clinical information systems are still not well understood. This study addresses this need by qualitatively investigating the relationships between the overall satisfaction with clinical information systems and five key aspects of clinical information systems, namely key functionalities, efficiency of use, intuitiveness of graphical user interfaces (GUI), communication, collaboration, and information exchange, and interoperability and compatibility issues. The findings resulting from both descriptive and thematic analyses show that clinical information systems are still in their infant stage and that their maturity is highly questionable. Simpler clinical information systems are likely to be more satisfying than more complex systems. System design and training provided are also key factors as the study finds.
\end{abstract}

Keywords: Clinical Information Systems, Interoperability, User Satisfaction, Usability, Graphical User Interface (GUI), IT Support, Training, Australia

\section{Introduction}

The healthcare industry is becoming one of the biggest markets for information technology. Most recently, Gartner has ranked the healthcare industry as the fifth highest spender on information systems/ information technology (IS/IT) at USD108 billion, with an increase of $2.7 \%$ compared to 2013 [1]. In Australia, similar trends are there with significant investments being made by various healthcare organizations for various technology solutions to provide and enable better care delivery [2-5].

IT user satisfaction has been shown in various academic and nonacademic publications as a determinant for successful IS/IT projects [6-9]. The focus of the vast majority of the current literature are on the factors that affect IT user satisfaction. For example, user involvement in systems development, perceived usefulness, user experience, organizational support and user attitude toward the IS were reported as key factors influencing user satisfaction in general with IS/IT [6] and that is in agreement with numerous other studies [8; $10 ; 11]$. While examining IS/IT user satisfaction in healthcare has a lengthy history [12-15], measuring user satisfaction with clinical information systems lags behind [16-18]. This examination of the overall user satisfaction with four clinical information systems qualitatively with the use of descriptive analysis identifies the relationships between the overall satisfaction and five aspects of clinical information systems, namely key functionalities, efficiency of use, intuitiveness of graphical user interfaces (GUI), communications, collaboration, and information exchange, and interoperability and compatibility issues. Each of these five areas are covered by a dedicated section in the survey as the following section explains.

\section{Methods}

An online survey was conducted to collect data on clinical IT user satisfaction at a tertiary, not-for-profit, private healthcare group in Australia. It is recognized as a pioneer hospital in diagnosis, treatment, care, and rehabilitation in the Australian context. The survey instrument was pre-tested for validity in a small pilot study.

The chosen healthcare group provides care for a vast range of medical conditions and diseases from the birth of a child to cardiac care, rehabilitation, hip and joint replacements, robotic surgery, and comprehensive cancer treatment, among others in around 40 specialties. 
it offers its medical services to patients mainly through two channels, the Emergency Department (ED), and the hospital's Visitor Medical Officers (VMOs) in the Australian terminology, where senior clinicians work for different healthcare providers without necessarily being employed by any of them. Rather, they practice as doctors and care providers to their patients by using the facilities of various hospitals.

In terms of its physical structure and interior facilities, the selected case has about ten sites and locations, mostly in suburbs that commonly are perceived to have populations ranking higher in the socioeconomic status. As of 2015, the selected case had about 150,000 total patient admissions, 90,000 surgical operations performed, and about half a million bed days. All of these activities are presented by the efforts of about 7000 employees, with about $60 \%$ of the workforce being nurses.

As recommended by Miller, three inputs can be used to determine the design of a user satisfaction survey namely the objective of the survey, the users' characteristics, and the resources available [19]. The objective of this survey was to develop a valid measurement of clinical IT user satisfaction. Given the varying nature, complexity, and functionality of the examined systems, the survey targeted a range of clinicians who use these systems to different extents. These include:

- Nurses: Given about $60 \%$ of the healthcare professional at the selected case are nurses, measuring their satisfaction is both beneficial, and key to the organizational success [20].

- (Doctors) VMOs: this group of healthcare professionals use their own clinical information systems as well as the clinical systems relevant to them at the selected case. Normally, they have sufficient power to use a particular information system or not to use it.

- Health information system specialists: this group of clinical information systems users handle the majority of clinical coding, generating clinical data sets, and also reporting the outcomes of various clinical specialties and measuring them against the organizational key performance indicators (KPIs).

As radiology, pathology, and pharmacy are all outsourced services at the selected case, none of these areas were surveyed, as they use their own information systems, and their interaction with the selected case's information systems are at minimum.

As the participants are predominately clinicians whose schedules are always busy, the design of the survey took this issues into consideration. The survey is relatively short and enables the users to skip sections that are irrelevant. As the selected case is a large healthcare group with multiple sites and locations, an online survey was the preferred option to collect the data. The respondents needed to click a hyperlink to the online survey prior to answering the questions, a detailed participant information sheet was presented to the respondents about the purpose of this study and how they can take part in it. A total of 107 respondents answered the questionnaire.

Due to missing information and incomplete responses, 76 valid questionnaires were used to present the results on clinical IT user satisfaction in the selected context of this study. The response rate was $38.3 \%$. This rate is approximately 3\% greater than the average response rate for studies that utilized data collected from organizations through questionnaire/survey methods as was measured by Barouch and Holtom [21]. Both thematic analysis [22-24], and descriptive analysis [25] were used to analyze the data collected through the survey.

The questions were focused on four main clinical information systems (Table 1) used by various clinicians at the selected healthcare group. The use of these four systems in the study are justified by their popularity (more used compared to other systems), and the time during which they have been in service (relatively longer than other systems not studied in this research).

This research is predominantly qualitative in nature. To enhance the internal validity of the results, the study adopts the six strategies proposed by Merriam and Tisdell [26] including:

- Triangulation: Mix-method approach are employed in this research.

- Adequate engagement in data collection: Data collection took over 20 months

- Researcher's position/ reflexivity: The researcher adopted a neutral position due to the exploratory nature of the study. No pre-defined assumptions or bias were adopted throughout the study.

- Peer review/ peer examination: This study was reviewed by a number of academics who are very familiar with the topic, including both the 
supervisory team and the reviewers of different publications produced based on this study.

- Audit Trail: The study employed this strategy at two levels; first, the researcher had an external adviser, and second, this study has produced a number of publications. All of which were read by independent readers through the blinded review processes, especially regarding data collection, data analysis, and results interpretations.

Table 1 The studied CISs in this study and their descriptions

\begin{tabular}{|c|c|c|c|c|}
\hline CIS $^{1}$ & Description & $\begin{array}{l}\text { Vendor } \\
\text { Purchased or } \\
\text { in-house } \\
\text { developed }\end{array}$ & $\begin{array}{l}\text { How long it } \\
\text { has been in } \\
\text { service }\end{array}$ & $\begin{array}{l}\text { User-input into } \\
\text { design }\end{array}$ \\
\hline $\begin{array}{l}\text { Computerized } \\
\text { Physician } \\
\text { Order Entry } \\
\text { (CPOE) }\end{array}$ & $\begin{array}{l}\text { This CPOE system is used at the } \\
\text { selected healthcare group to } \\
\text { facilitate electronic scheduling for } \\
\text { oncology patients which was } \\
\text { originally a paper-based system at } \\
\text { multiple sites. And to help with } \\
\text { designing its chemotherapy } \\
\text { protocols and related processes such } \\
\text { as nurse assessment and notes and } \\
\text { radiology planning for cancer } \\
\text { patients. }\end{array}$ & $\begin{array}{l}\text { Developed in } \\
\text { USA and } \\
\text { customized by } \\
\text { vendor to fit the } \\
\text { Australian } \\
\text { healthcare } \\
\text { system } \\
\text { Purchased }\end{array}$ & 4 years & $\begin{array}{l}\text { No user-input from } \\
\text { the selected case } \\
\text { were taken into } \\
\text { consideration when } \\
\text { designing the } \\
\text { system. } \\
\text { Domesticating the } \\
\text { system to fit the } \\
\text { Australian } \\
\text { standards though } \\
\text { had minimal input } \\
\text { by the users. }\end{array}$ \\
\hline $\begin{array}{l}\text { Scanned } \\
\text { Medical } \\
\text { Records } \\
\text { (SMR) } \\
\text { System }\end{array}$ & $\begin{array}{l}\text { SMR is a clinical information system } \\
\text { which is seen as a cornerstone of the } \\
\text { vision of electronic medical records } \\
\text { (EMRs). The system is customized } \\
\text { and designed to make daily clinical } \\
\text { practice easier by enabling higher } \\
\text { speed and quality in capturing and } \\
\text { distributing health information. The } \\
\text { system is web-based and consists of } \\
\text { a number of modules such as } \\
\text { scanning medical records, e-forms, } \\
\text { e-results, and other modules around } \\
\text { medical images and medications. } \\
\text { The main functions of the system } \\
\text { that currently are being used in the } \\
\text { selected case are scanning medical } \\
\text { records, coding clinical episodes, } \\
\text { and tracking paperwork around } \\
\text { admissions. The system is used and } \\
\text { fully interfaced by seven different } \\
\text { pathology and three radiology } \\
\text { providers. From a hardware } \\
\text { perspective, the system comprises } \\
\text { about } 30 \text { document scanners and } \\
\text { more than } 155 \text { computers. }\end{array}$ & $\begin{array}{l}\text { An Australian } \\
\text { software vendor. } \\
\text { Minimal tailoring } \\
\text { by vendor to fit } \\
\text { the organization. } \\
\text { Purchased }\end{array}$ & 7 years & $\begin{array}{l}\text { No user-input from } \\
\text { the selected case } \\
\text { were taken into } \\
\text { consideration when } \\
\text { designing the } \\
\text { system. However, } \\
\text { there was minimal } \\
\text { user input when } \\
\text { tailoring the } \\
\text { system. The later } \\
\text { updates, took more } \\
\text { insights by the } \\
\text { users into } \\
\text { consideration. }\end{array}$ \\
\hline
\end{tabular}

\footnotetext{
${ }^{1}$ For ethical considerations, the names of the studied CISs are pseudonym
} 


\begin{tabular}{|c|c|c|c|c|}
\hline CIS $^{1}$ & Description & $\begin{array}{l}\text { Vendor } \\
\text { Purchased or } \\
\text { in-house } \\
\text { developed }\end{array}$ & $\begin{array}{l}\text { How long it } \\
\text { has been in } \\
\text { service }\end{array}$ & $\begin{array}{l}\text { User-input into } \\
\text { design }\end{array}$ \\
\hline $\begin{array}{l}\text { Clinical Audit } \\
\text { Tool (CAT) }\end{array}$ & $\begin{array}{l}\text { Used as an electronic clinical audit } \\
\text { tool. Aims at allowing doctors and } \\
\text { other clinical users to create records } \\
\text { for each operation or admission that } \\
\text { occurs within each specialty. The } \\
\text { record will include a structured data } \\
\text { set, representing all of the } \\
\text { information pertinent to clinical } \\
\text { audit within that specialty. } \\
\text { Recently, CAT for General Surgery } \\
\text { and Spinal Surgery went live at the } \\
\text { selected case. Both of these projects } \\
\text { have extensive clinical content } \\
\text { relevant to each specialty. They are } \\
\text { also both integrated directly with the } \\
\text { group's PAS via HL7. The } \\
\text { integration includes patient } \\
\text { demographics, diagnosis, theatre } \\
\text { details and discharge information. }\end{array}$ & $\begin{array}{l}\text { An Australian } \\
\text { software vendor. } \\
\text { Significant } \\
\text { tailoring in } \\
\text { conjunction with } \\
1-2 \text { key } \\
\text { informants who } \\
\text { were users of the } \\
\text { data generated by } \\
\text { the system. } \\
\text { Purchased }\end{array}$ & 2.5 years & $\begin{array}{l}\text { The version of } \\
\text { system used by the } \\
\text { selected case was } \\
\text { developed in } \\
\text { collaboration with } \\
\text { the clinical auditing } \\
\text { team at the selected } \\
\text { case. All updates } \\
\text { and changes are } \\
\text { being undertaken } \\
\text { with taking user- } \\
\text { input into its } \\
\text { design. }\end{array}$ \\
\hline $\begin{array}{l}\text { Radiology } \\
\text { Results } \\
\text { Viewer } \\
\text { (RRV) }\end{array}$ & $\begin{array}{l}\text { A web-based application that is } \\
\text { embedded within SMR to enable } \\
\text { viewing medical images. It supports } \\
\text { multi-modality readings and has a } \\
\text { customized toolset to increase the } \\
\text { efficiency of results reading. }\end{array}$ & $\begin{array}{l}\text { An Australian } \\
\text { software vendor. } \\
\text { A small amount } \\
\text { of user input } \\
\text { from selected } \\
\text { users occurred to } \\
\text { address minor } \\
\text { tailoring needs. } \\
\text { Purchased }\end{array}$ & 6 years & $\begin{array}{l}\text { No user-input from } \\
\text { the selected case } \\
\text { were taken into } \\
\text { consideration when } \\
\text { designing the } \\
\text { system. }\end{array}$ \\
\hline
\end{tabular}




\section{Results}

This section presents the results from the survey in two areas, namely the overall user satisfaction with the examined clinical information systems, and user satisfaction with the level of technical support and training provided.

\subsection{CIS User Satisfaction}

The respondents were first asked on how often they use clinical information systems (CIS) in their daily work with patients and/or their medical records. To avoid any confusion, the survey defined a CIS as "any kind of clinical information and communication technology (ICT) system to support patient care (e.g. managing patient information and paperwork, patients' medication, diagnostic findings, required investigations etc.)". $51 \%$ of the respondents stated they had used CISs several times per day (Figure 1).

The most used CIS in the examined group of systems was SMR with $97 \%$ of the respondents answered with Yes on the question whether they use this system in their daily work. RRV was the second common CIS with $47 \%$, followed by CPOE with $13 \%$, and CAT with only $3 \%$ of the population said they had used it in their daily work (Figure 2).

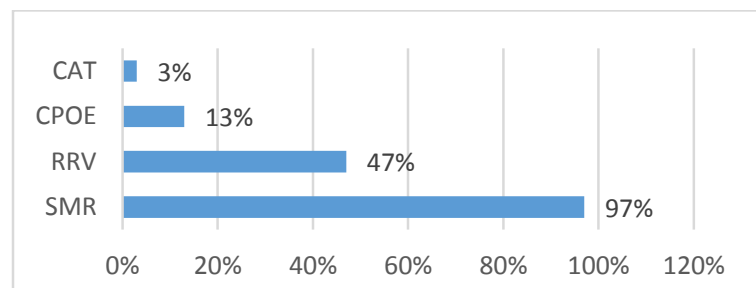

Figure 2 The percentage of users who use the examined CISs for their daily work

Answering the question on how the participants were satisfied with the 4 examined systems, RRV was the most satisfying CIS with $63 \%$ of the participants were satisfied and $6 \%$ very satisfied with it as Table 2 summarizes.

Table 2 The overall satisfaction with the examined CISs in the selected case

\begin{tabular}{|l|l|l|l|l|l|}
\hline CIS & $\mathbf{1}^{\mathbf{2}}$ & $\mathbf{2}$ & $\mathbf{3}$ & $\mathbf{4}$ & $\mathbf{5}$ \\
\hline CPOE & $50 \%$ & $50 \%$ & & & \\
\hline SMR & $22 \%$ & $22 \%$ & $23 \%$ & $33 \%$ & \\
\hline CAT & & & $100 \%$ & & \\
\hline RRV & & $6 \%$ & $25 \%$ & $63 \%$ & \\
\hline
\end{tabular}

2 1: Very dissatisfied, 2: satisfied, 3: neutral, 4: satisfied, 5: very satisfied.

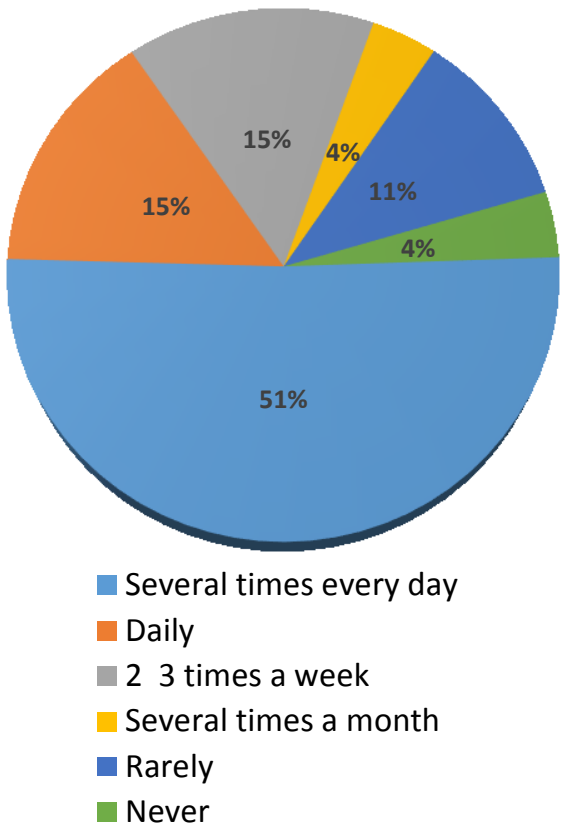

Figure 1 How often CISs are used by the respondents

In order to identify the reasons behind these levels of satisfactions, the respondents were asked to evaluate sets of statements on their use of the examined systems to perform their tasks. From a system functionality perspective, these statements covered providing decision-making support, preventing medication errors, visualizing data and information to facilitate better work flow, improving health outcomes, improving access to important clinical information (lab, radiology, pathology) and documenting these information, improving the quality of information available, and reducing duplicity of effort.

As RRV and CPOE were the most and least satisfying CIS, we compared the responses of the statements regarding these two systems.

The comparison covered five primary aspects: key functionalities, efficiency of use, intuitiveness of graphical user interfaces (GUI), communication, collaboration, and information exchange, and interoperability and compatibility issues. The summary of this comparison in the area of key functionalities is presented in Table 3 , where 1 is strongly disagree, 2 is disagree, 3 is neutral, 4 is agree, and 5 is strongly agree. 
Table 3 A comparison between the most and least satisfying CIS in the selected case

\begin{tabular}{|c|c|c|c|c|c|c|}
\hline Statement & CIS & 1 & 2 & 3 & 4 & 5 \\
\hline \multirow{2}{*}{$\begin{array}{l}\text { This CIS provides support for decision making } \\
\text { (reminders and warnings) }\end{array}$} & CPOE & $50 \%$ & & & $50 \%$ & \\
\hline & RRV & $20 \%$ & $47 \%$ & $13 \%$ & $20 \%$ & \\
\hline \multirow{2}{*}{ This CIS helps prevent medication errors } & CPOE & $50 \%$ & & & $50 \%$ & \\
\hline & RRV & $31 \%$ & $44 \%$ & $19 \%$ & $6 \%$ & \\
\hline \multirow{2}{*}{$\begin{array}{l}\text { This CIS provides a proper summary view (e.g. } \\
\text { daily treatment chart) of the patient. }\end{array}$} & CPOE & $50 \%$ & $50 \%$ & & & \\
\hline & RRV & $38 \%$ & $31 \%$ & $25 \%$ & $6 \%$ & \\
\hline \multirow{2}{*}{ This CIS helps to improve health outcomes. } & CPOE & & $50 \%$ & $50 \%$ & & \\
\hline & RRV & & $13 \%$ & $19 \%$ & $50 \%$ & $19 \%$ \\
\hline \multirow{2}{*}{$\begin{array}{l}\text { This CIS improves my access to important } \\
\text { clinical information (lab, radiology, pathology) }\end{array}$} & CPOE & $50 \%$ & $50 \%$ & & & \\
\hline & RRV & & & $19 \%$ & $44 \%$ & $38 \%$ \\
\hline \multirow{2}{*}{$\begin{array}{l}\text { This CIS improves the quality of information } \\
\text { available }\end{array}$} & CPOE & $50 \%$ & $50 \%$ & & & \\
\hline & RRV & & & $25 \%$ & $56 \%$ & $19 \%$ \\
\hline \multirow{2}{*}{ This CIS reduces duplicity of effort } & CPOE & $50 \%$ & $50 \%$ & & & \\
\hline & RRV & & $6 \%$ & $50 \%$ & $31 \%$ & $13 \%$ \\
\hline \multirow{2}{*}{$\begin{array}{l}\text { This CIS makes documentation of clinical } \\
\text { information easier }\end{array}$} & CPOE & $50 \%$ & $50 \%$ & & & \\
\hline & RRV & $6 \%$ & $13 \%$ & $19 \%$ & $50 \%$ & $12 \%$ \\
\hline
\end{tabular}

Similar comparisons showed that $\mathrm{CPOE}$ has challenges with efficiency of use, intuitiveness, and supporting information exchange, communication, and collaboration in the clinical space. Although the majority of the users thought CPOE was a reliable system, there as an agreement that the system is not easy to communicate with other systems in a way that enables interoperability. On the other hand, RRV seemed to be accepted by the majority of the respondents in terms of its key functionalities (Table 3), efficiency of use compared with using paper to facilitate the daily tasks, intuitiveness of GUI, and supporting collaboration in the clinical space. However, RRV seemed to be struggling in terms of supporting access to information in a timely manner.

\subsection{Training and Technical Support Satisfaction}

The respondents were surveyed on their satisfaction with IT equipment and systems (hardware and software) in the work place (Figure 3).

The selected case has an IT-hotline in place, the majority of the respondents said they had rarely used this service $(79 \%)$ and $8 \%$ said they had never used it. $29 \%$ of the respondents stated that their IT problems were solved immediately over the phone (Figure 4).

Similarly, IT-on-call-duty is never used by the respondents. This service relates to IT-emergencies and interruptions during the night and on weekends. Asked about the level on onsite support $50 \%$ of the respondents were neutral, $35 \%$ were satisfied, and $10 \%$ were very satisfied.

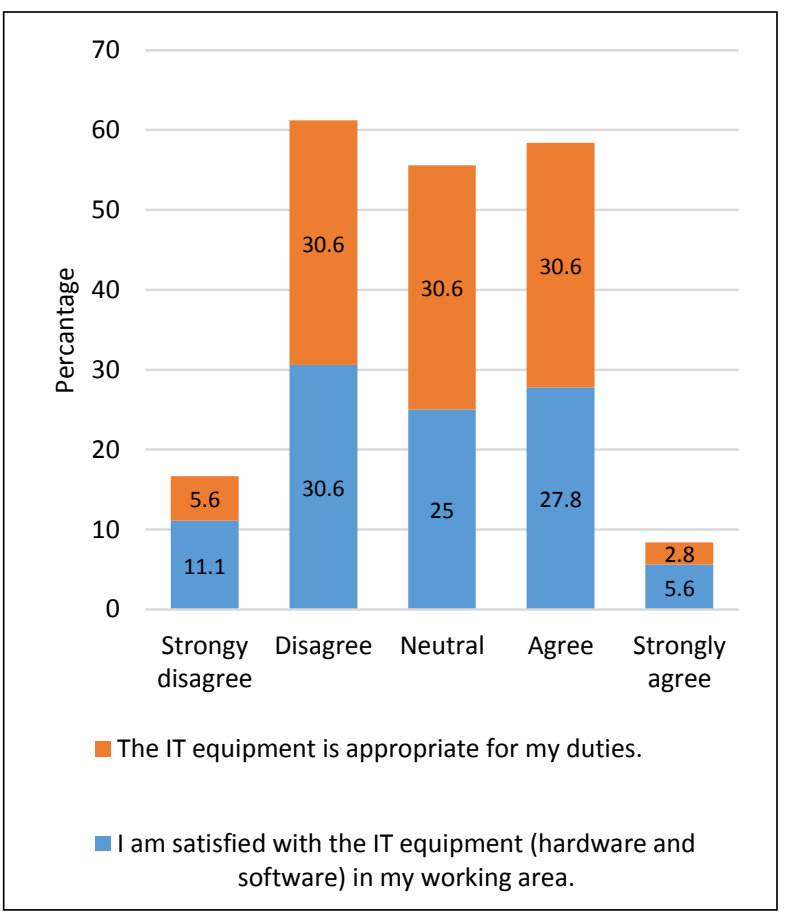

Figure 3 The Overall Satisfaction with IT equipment at the selected case 


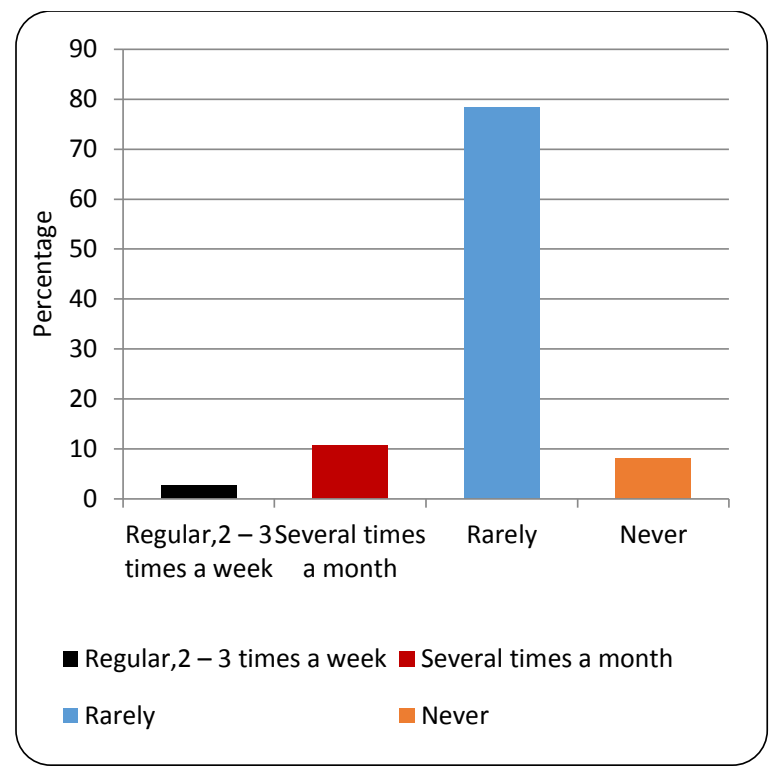

Figure 4 The use IT hotline for technical support

The nature of healthcare seems to have caused some problems with the ordinary model of IT technical support (within working hours). According to a number of the respondents who work in the emergency department, a few cases were reported where no proper technical support after hours was available, despite the IT-on-call-duty is designed to treat these situations: " $A$ lot of ED shifts are 'out of hours' and there is very little support at these times. I have had to send a staff member home because he could not log on and he could not get this issue rectified". Similar views came from another respondent: "Issues arise out-of-hours and lack of IT help can be frustrating. There are process issues which invariably always require re-work from our end to ensure new employees are set-up correctly on [Patient Administration System (PAS)] and access rights. This may not be entirely IT domain, but it's frustrating that a common process is not embedded despite years of the same issues cropping up".

The survey then asked on the amount of trainings the respondents had attended in the last 12 months. The majority of the respondents stated they had received no training at all, and around $87 \%$ of them were dissatisfied with IT training. Most of the respondents found the training topic an entrance to express their frustrations with the design of their clinical information systems. One respondent notes: "By definition a good IT system is intuitive. The training should be built into the system". Another indicates similar views and compares these systems with other systems that are used daily with no training needed: "IT training is important, but designing software that doesn't need training is much more important. Designers realize this, and you can easily find countless examples on the internet. For example, Facebook, Instagram, Weebly, Tumblr, video and photo editing software etc... With no training at all, I am able to use these programs to at least $90 \%$ of their capacity. Compare that to something like [SMR]... [SMR] is so hard to use, I seldom bother opening it". Another respondent explains the roots of this very problem: "The problem with almost all clinical information systems is that they have been created by software engineers, rather than designers. Any piece of software should be designed with the person who actually uses it in mind. This is what designers do. This is why designers should make software. Engineers generally have absolutely no idea what users need. Engineers are good at sorting out technical problems, but they are hopeless at designing products, including software, with the user in mine. [CPOE] is a classic example of this problem. It's hard to use, it's non intuitive, the interface is ugly and messy. It's illogical. It requires hours of training and constant use to get god at using it. Most doctors don't sit down for hours and play with it. That's why we find it difficult, frustrating, and dangerous".

\section{Discussion}

This study was performed to qualitatively gain a better understanding of the levels of user satisfaction with 4 clinical information systems at an Australian healthcare group. Descriptive and thematic analyses were used in this study. The four clinical information systems were of different objectives, the CPOE helps with facilitating electronic drug prescribing, CAT helps create an electronic record for every and each admission to the healthcare group, RRV enables fetching radiology images electronically, and SMR is designed as a system that enables storing all medical records at the selected case in a scanned form. These systems were examined against 5 primary areas of investigation: key functionalities, efficiency of use, intuitiveness of graphical user interfaces (GUI), communication, collaboration, and information exchange, and interoperability and compatibility issues.

The majority of the participants in this study were satisfied with RRV and dissatisfied about CPOE. RRV is the least expensive system within the examined group of clinical information systems. Yet, it is the most satisfactory system to the majority of its users. The analysis shows that CAT is not widely used at the selected case, and all of its users were neutral about it. This is understandable as the system had been recently implemented at the time of data collection and building conclusions about it might be practically challenging. The most utilized system was SMR with about $97 \%$ of the participants were using it. The system is seen as a 
necessary step to EMRs by digitizing all medical records around all admissions occur at the different sites of the group. Currently, it is used mainly to scan medical records, code clinical episodes, and track paperwork around every admission to all sites of the group.

The system is relatively inexpensive to operate and maintain and is easy to use as described by the majority of the participants. This system, however, suffers from its limited functionality. It is understood that it does not offer the medical records in a way that enables data analytics or business intelligence. This limitation makes this system incapable of coping with today's digital requirements of healthcare delivery. Further, although the system is used group-wide, it only covers inpatient, leaving outpatients out of its scope. The most satisfying system as the results show was RRV, with almost $70 \%$ of the participants were satisfied and very satisfied with it. A number of characteristics of RRV significantly contributed to this high satisfaction level as the results show. These include supporting information exchange, communications and collaboration in the clinical space, intuitiveness of user interface, efficiency of use, and the key functionality of the system in terms of improving access to important clinical information as well as providing the clinicians with quality information that support their decisions around respective care episodes. In addition, documenting clinical information is also easily enabled by using RRV as the results show, which contributed to the high level of satisfaction with using this system.

In contrast, $\mathrm{CPOE}$ was the least satisfactory system for the participants with $50 \%$ of the participants were dissatisfied and $50 \%$ were very dissatisfied with it. CPOE is a sophisticated system that is used primarily by a limited number of clinicians in the area of cancer care for drug prescribing and patient scheduling, which explains the low percentage of use (13\%), unlike SMR for example which is used by all clinicians in the selected case. The main factors that contributed to lower levels of satisfaction with this system relate to its functionality, ease of use, technical problems, and intuitiveness of the user interface. Indeed, $100 \%$ of the participants stated that working on paper is more efficient that using the system, that is due to technical problems face the clinicians with logging in (takes extended times), entering data and extracting information of the system. As these activities tend to be lengthy procedures and require a broader bandwidth by the clinicians to deal with, $100 \%$ of the participants agreed that the use of this system is distracting them from paying attention to their patients. Further, the studied CPOE does not seem to support information exchange, communication and collaboration within the clinical domain, with $100 \%$ of the participants agreeing that this system does not support delivering information about patients to clinicians within or across healthcare providers.

The level of training and technical support on spot have also contributed to the overall satisfaction of CIS users at the selected case. The results that the majority of participants were satisfied with IS/IT equipment they have and thought they were appropriate for the type of work assigned to them. However, the level of training both in-house and external were way below the expectations and needs of the users as the results show. Indeed, both CPOE and CAT received lower satisfaction scores due to lacking a proper training that tracks the progress of their utilization of the system and realizing its benefits. The overall satisfaction seems also to be affected by the level of technical support provided on spot. Although all of the participants were happy about the level of help desk provided to them, this support is limited to normal technical issues. With more complex enquiries about sophisticated systems the technical support seemed to struggle to meet the actual needs of users. Two on the main facilities available for users to use to receive technical support were barely used. These are the hotline and IT-on-call-duty services. It is not clear from the results why these are not utilized by the users, which needs a further investigation.

Finally, an unexpected finding that resulted from the comparison of the systems as shown in Figure 5 includes that the more flexible or less structured the system as

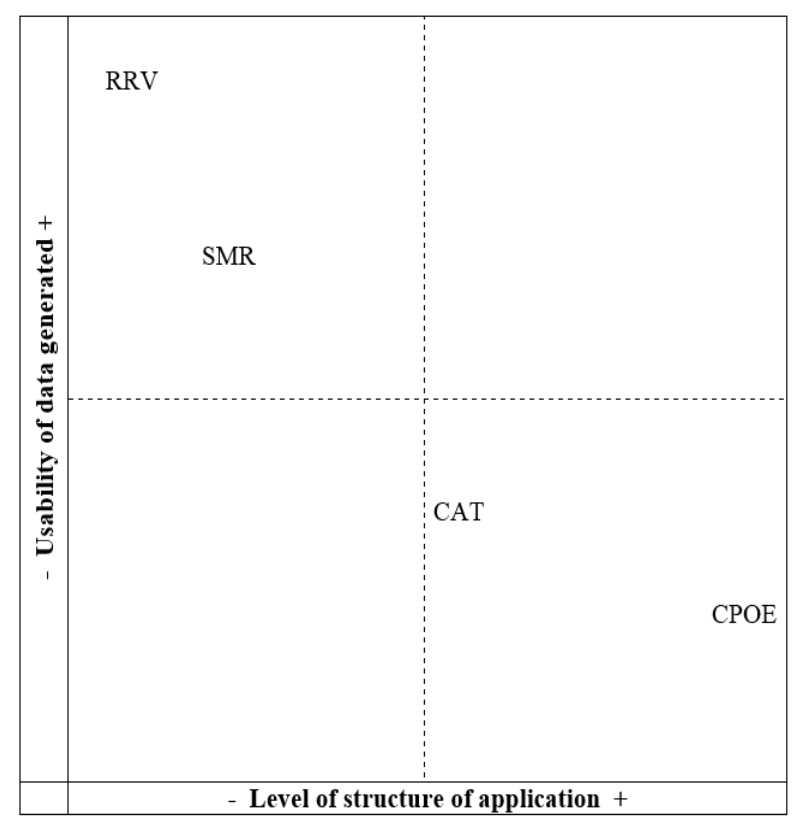

Figure 5 The level of structure and usability of generated data for the four compared systems 
well as the greater usefulness of the generated data is the most desired result.

\section{Conclusion}

This study set out to evaluate the overall user satisfaction with clinical information systems at an Australian tertiary, not for profit, private healthcare group. Different constructs were considered to evaluate the user satisfaction. The results show that intuitive, easy-to-use, and collaboration enabling systems are more likely to satisfy their users. The level of technical support and training seem to play key roles in determining user satisfaction in the clinical domain.

The implications of this study cover both theory and practice. Theoretically, the survey instrument may be used by various types of hospitals and healthcare organizations in general to understand the overall user satisfaction with their clinical information systems. This is particularly timely with the ever increasing trend to implement EMRs in Australia and globally. One of the factors that make this survey valid for different contexts is its coverage to various aspects around the usefulness of clinical information systems in today's healthcare delivery. This includes the systems compatibility with clinicians' tasks in terms of core functionalities, efficiency of use, intuitiveness of user interfaces, accessibility of information, support of collaboration, interoperability, compatibility and reliability of the studied systems.

Practically, the results of this study help decision makers and top management at hospitals to better understand the actual needs of clinical information systems' users to better utilize CIS as a contemporary assets $[27 ; 28]$. This is crucial with the increased investments in IS/IT in healthcare. Today, healthcare is ranked fourth in investing in investing in IS/IT after retail, banking and securities, and education [1]. The study also shows that CIS users are likely to be satisfied if the systems are intuitive, easy to use, and enable better access to medical information in a timely manner. This agrees with numerous studies in the literature. See for example $[5 ; 12-14 ; 20 ; 29]$. The results also show that decision makers will need to pay attention to training and technical support channels. The amount and quality of training are key aspects of user satisfaction as the results show. While it is not clear why the vast majority of the participants in this study did not use the IT hotline and IT-on-call-duty services based on the data, further investigation on this matter is likely to clarify this behavior and how to minimize its impact on the overall user satisfaction with clinical information systems.

This study has several limitations. Firstly, the sample size is relatively small; however this is not atypical given the time pressures on and priorities of clinicians, In addition, it only covers one healthcare organization. Secondly, the structure of the survey is predominantly qualitative and meant to evaluate the overall user satisfaction with their clinical information systems. Thirdly, the compared systems are largely different in terms of their level of complexity, functionality, and popularity at the selected case. Hence, the usefulness of comparison is limited.

Future research directions include; fine tuning the survey to quantitatively determine user satisfaction based on its constructs in this study, i.e. systems compatibility with clinicians' tasks in terms of core functionalities, efficiency of use, intuitiveness of user interfaces, accessibility of information, support of collaboration, interoperability, compatibility and reliability of the studied systems. A comparison between different healthcare providers is also beneficial and planned to be conducted in future. Also, examining the impact of user satisfaction on the business value of IS/IT in healthcare and moderating role of proper training, coaching, and change management practices on this relationship is planned to be the second phase of this study.

\section{References}

[1] I. Gartner, Gartner Says Worldwide IT Spending Across Vertical Industries to Decline 3.5 Percent in 2015, in, Gartner, STAMFORD, Conn., 2015.

[2] P. Haddad, J. Schaffer, and N. Wickramasinghe, Evaluating Business Value of IT in Healthcare: Three Clinical Practices from Australia and the US, in: MEDINFO 2015: EHealth-enabled Health: Proceedings of the 15th World Congress on Health and Biomedical Informatics, IOS Press, 2015, p. 183.

[3] E. Willis, L. Reynolds, and H. Keleher, Understanding the Australian health care system, Elsevier Health Sciences, 2016.

[4] C. Pearce and M.C. Haikerwal, E-health in Australia: time to plunge into the 21 st century, Med J Aust 193 (2010), 397-398.

[5] P. Haddad, M. Gregory, and N. Wickramasinghe, Evaluating Business Value of IT in Healthcare in Australia: The Case of an Intelligent Operational Planning Support Tool Solution, in: Bled 2014, AIS Electronic Library, 2014.

[6] M.O. Adam Mahmood, J.M. Burn, L.A. Gemoets, and C. Jacquez, Variables affecting information technology end-user satisfaction: a meta-analysis of the empirical literature, International Journal of Human-Computer Studies 52 (2000), 751-771.

[7] M. Maldonado and V. Sierra, User satisfaction as the foundation of the success following an ERP adoption: an 
empirical study from Latin America, International Journal of Enterprise Information Systems (IJEIS) 9 (2013), 77-99.

[8] Y.K. Dwivedi, K.K. Kapoor, M.D. Williams, and J. Williams, RFID systems in libraries: An empirical examination of factors affecting system use and user satisfaction, International Journal of Information Management 33 (2013), 367-377.

[9] U. Abelein and B. Paech, Understanding the influence of user participation and involvement on system success-A systematic mapping study, Empirical Software Engineering 20 (2015), 28-81.

[10] B. Xiong, M. Skitmore, B. Xia, M.A. Masrom, K. $\mathrm{Ye}$, and A. Bridge, Examining the influence of participant performance factors on contractor satisfaction: A structural equation model, International journal of project management 32 (2014), 482-491.

[11] P. Bharati and A. Chaudhury, Product customization on the web: an empirical study of factors impacting choiceboard user satisfaction, Bharati, P. and Chaudhury, A.(2006), "Product Customization on the Web: An Empirical Study of Factors Impacting Choiceboard User Satisfaction," Information Resources Management Journal 19 (2015), 6981.

[12] K.G. Adler, How to successfully navigate your EHR implementation, Family practice management 14 (2007), 33.

[13] E. Ammenwerth, C. Iller, and C. Mahler, ITadoption and the interaction of task, technology and individuals: a fit framework and a case study, BMC Medical Informatics and Decision Making 6 (2006), 3.

[14] K.M. Cresswell, D.W. Bates, and A. Sheikh, Ten key considerations for the successful implementation and adoption of large-scale health information technology, Journal of the American Medical Informatics Association 20 (2013), e9-e13.

[15] L. Nguyen, P. Haddad, F. Mogimi, K. Coleman, B. Redley, M. Botti, and N. Wickramasinghe, Developing an Information System for Nursing in Acute Care Contexts, in: PACIS 2015 Proceedings, Singapore, 2015.

[16] M. Van Der Meijden, H.J. Tange, J. Troost, and A. Hasman, Determinants of success of inpatient clinical information systems: a literature review, Journal of the American Medical Informatics Association 10 (2003), 235243.

[17] D. Garcia-Smith and J.A. Effken, Development and initial evaluation of the clinical information systems success model (CISSM), International Journal of Medical Informatics 82 (2013), 539-552.
[18] M.W. Friedberg, P.G. Chen, K.R. Van Busum, F. Aunon, C. Pham, J. Caloyeras, S. Mattke, E. Pitchforth, D.D. Quigley, and R.H. Brook, Factors affecting physician professional satisfaction and their implications for patient care, health systems, and health policy, Rand health quarterly 3 (2014).

[19] L. Miller, User satisfaction surveys, Australasian Public Libraries and Information Services 17 (2004), 125.

[20] N. Wickramasinghe, B. Kent, F. Moghimi, M. Stien, L. Nguyen, B. Redley, N. Taylor, and M. Botti, Using Technology Solutions to Streamline Healthcare Processes for Nursing: The Case of an Intelligent Operational Planning Support Tool (IOPST) Solution, in: Lean Thinking for Healthcare, N. Wickramasinghe, L. Al-Hakim, C. Gonzalez, and J. Tan, eds., Springer New York, 2014, pp. 405-430.

[21] Y. Baruch and B.C. Holtom, Survey response rate levels and trends in organizational research, Human Relations 61 (2008), 1139-1160.

[22] M. Vaismoradi, H. Turunen, and T. Bondas, Content analysis and thematic analysis: Implications for conducting a qualitative descriptive study, in, 2013, pp. 398-405.

[23] H. Joffe, Thematic analysis, Qualitative research methods in mental health and psychotherapy: A guide for students and practitioners 1 (2012), 210-223.

[24] V. Braun and V. Clarke, Using thematic analysis in psychology, Qualitative research in psychology 3 (2006), 77101.

[25] R.F. Woolson and W.R. Clarke, Descriptive Statistics, Hoboken, NJ, USA: John Wiley \& Sons, Inc., Hoboken, NJ, USA, 2011.

[26] S.B. Merriam and E.J. Tisdell, Qualitative research: A guide to design and implementation, John Wiley \& Sons, 2015.

[27] R.G. Fichman and N.P. Melville, How PostureProfile Misalignment in IT Innovation Diminishes Returns: Conceptual Development and Empirical Demonstration, Journal of Management Information Systems 31 (2014), 203240 .

[28] M.J. Davern and R.J. Kauffman, Discovering potential and realizing value from information technology investments, Journal of Management Information Systems 16 (2000), 121-143.

[29] L. Nguyen, P. Haddad, H. Mogimi, K. Coleman, B. Redley, M. Botti, and N. Wickramasinghe, Developing an Information System for Nursing in Acute Care Contexts, (2015). 